nated, volume-oriented, resource-sharing electronic ordering process.

For information relative to BISAC transmission formats or BISAC membership, write to: Book Industry Systems Advisory Committee, 160 Fifth Ave., Suite 604, New York, NY 10010.

For input to BISAC purchase order formats, write to: J. K. Long, Chairman, BISAC P.O. Subcommittee, c/o OCLC, Inc., 6565 Frantz Rd., Dublin, OH 43017. (Mr. Long is also the library or network representative on the ISBN advisory council.)

For input to the ANSI Z39 P.O. transmission formats, write to: Mr. E. Muro, Chairman, Subcommittee U, c/o Baker \& Taylor Co., 6 Kirby Ave., Somerville, NJ 08876.

For problems with the ISBN and SAN, write to: Mr. Emory I Koltay, International Standard Book Numbering Agency, 1180 Avenue of the Americas, New York, NY 20036.

\section{Microcomputer Backup to Online Circulation}

\section{Sheila INTNER: Emory University, Atlanta, Georgia.}

Our primary objective in purchasing microcomputer systems for the Great Neck Library was to provide a better alternative to paper and pencil checkouts when our minicomputer-based CLSI LIBS 100 automated circulation system was down. Two difficult and lengthy downtime periods occurring shortly after going online convinced the administration that public service should not be jeopardized because of system failure. After investigation of the backup systems vended by Computer Translation, Inc. ${ }^{1}$ two of them were purchased in November 1980 .

Computer Translation, Inc. (CTI) sells a turnkey backup system based on an Apple II Plus microcomputer, with two mini-disk drives using $5^{1 / 4}$ " floppy diskettes, a TV monitor, and a switching system connecting the Apple to the LIBS 100 console and terminals. Software designed to interface with the CLSI system is part of the package. The backup collects and stores data for check-ins and checkouts and then dumps them into the database by simulating a terminal when the mini-main-frame is operational again. This requires dedicating a terminal to this process until complete. It can also be used alone as a portable unit for circulation purposes, or with any of the many Applesoft packages available, or with an Applesoft program of the user's own design.

Our initial experience in Great Neck was with a borrowed demonstration system, set up by a sympathetic CTI representative on the spur of the moment in tandem with and connected to the Main Library checkout station's CRT laser terminal after several days of downtime. The circulation staff cheered as the familiar prompts appeared on both screens. They used the CLSI equipment which they were accustomed to operating and the computer room staff learned to operate the CTI system. The ease with which the Apple could be transported to different locations in the building and the immediate relief it gave wherever it was connected, sometimes one checkout station, sometimes another, led us to put off deciding on a permanent installation at first. We thought it might be more advantageous to keep it on a rolling cart and use it wherever a terminal was down, or wherever the traffic appeared to be heaviest. We continued in this manner for a while even after both of our own Apple systems were delivered.

It soon became apparent that the Apple and its accompaniments, especially the switching system with its dangling cables, was a nuisance at the checkout counter. People with piles of books or records tended to nudge it dangerously close to the edge or jiggle its connections loose. The circulation staff didn't like waiting until someone from the computer room could be spared to bring up the system, secure the connections, and turn on the Apple. Also, although the Apple is a very reliable instrument which has given us negligible downtime, bumpy rides over various floors, carpets, lintels, and textured tiles occasionally loosened its chips and rendered it, too, inoperative.

CTI representatives were called in to make a more permanent installation for the Apple in our computer room, a simple operation requiring some additional cable. Se- 
lection of the terminals to be attached as alternate backup or dumping sites was not so easy, however. The choice of the primary backup site was not a problem, since one of the two checkout stations flanking the main door was fairly obvious. But the second terminal which would be preempted for dumping was a more difficult decision. Dumping sessions vary in length depending on the number of records to be processed and the activity on the rest of the LIBS 100 system. In our library, we find it takes about an hour to dump 100 to 150 transactions. This appears to be slower than average and may well be due to the extremely high level of system activity. Thus, dumping 1,000 transactions would take a full working day. We had been online for such a short time that great backlogs of patron and material data entry from new registrants and unconverted books had developed and were a high priority item. Neither the circulation department, which was handling registrations, nor technical services, which was handling materials, felt they could afford to lose much terminal time for dumping. Thus, the reference department's information desk terminal was reluctantly chosen as the alternate terminal on the grounds that they only did inquiries for materials which borrowers could locate by means of searching the catalog and making trips to the shelves. If necessary, information desk personnel could step across the aisle to the circulation department and use a terminal there.

The permanent installation was set up in this way for one backup system, while the other one remained mobile in the event we wanted to use it at one of our three branches. Only the switching box and cables were really unmovable. The Apple, drives, and monitor could still be disconnected and moved about at will.

Experience over the last few months with this arrangement demonstrated that, all things considered, it is unwise to attach two public service terminals to one Apple, in spite of the pressure it puts on behind-thescenes operations to lose terminal time in the event of an extensive dump. The reaction of the public to being told a terminal that usually helped them was inoperative has been so negative it outweighed the de- lays in data entry. Therefore, a change in the current configuration will soon be made.

Meanwhile, we realized the second backup system was not being used to greatest advantage. When the LIBS 100 was down, the next most pressing demand after main library checkouts were checkouts at the largest branch, located near the railroad station. We were collecting about thirty transactions an hour or less at other locations in the main building while the station branch staff were writing down twice that amount or more and explaining to their public that the computer was down. It seemed important to pursue the possibility of connecting one of the station branch's terminals to the second Apple while keeping the Apple itself in the computer room in the main library. Not only was there even less space in the branch for another piece of hardware on their counter, but staff training and hardware control presented a greater problem since many more part-time people were employed there.

CTI worked on the problem for about two months, resolving it through the addition of a modem to the basic configuration. In this new installation, which we did ourselves with phone assistance from CTI, and which has been operational for three weeks as of this writing, the dedicated phone line connector for the branch terminal is removed from its port on the LIBS 100 console and inserted into one of the switching box connectors. The Apple is turned on as usual and the CRT laser terminal at station branch appears to operate normally. In fact, it operates so closely to its usual LIBS 100 mode that staff members forget they are not online with the LIBS and call up to find out why inquiries don't work.

We are still experiencing a significant amount of downtime with our LIBS 100. Some of this is attributable to our relatively full storage, requiring us to perform housekeeping routines frequently, but the rest is a result of system failure. Now, however, because of the Apples, this causes far less anguish in the circulation department. When the LIBS 100 goes down, the permanently connected backups are switched on in the computer room by their staff and circulation clerks continue checking materials out 
on their regular CLSI equipment in the main library and station branch. On days when housekeeping chores are scheduled, the console operator's job includes turning on the Apples so we can begin serving the public when the doors open at 9:00 a.m. Unless downtime persists for more than a day, no other routines are done except checkouts. Under some circumstances, certain materials might be checked in on the Apple, but it is not desirable to do this for newer materials on which holds may have been placed.

When the LIBS 100 is online again, the checkout station is switched back to normal mode and the Apple takes over the information desk's port for dumping, rendering that terminal inoperative. Dumping continues around the clock until all transactions have been processed from both Apples. Normal activities proceed at all other terminals. Diskettes are dumped in chronological order. As the dumping process operates, a file of transactions eliciting error or exception messages from the LIBS 100 is created on the Apple diskette. This file is available for attention at a later time for manual entry into the database.

The chief asset of the dumping process is the accuracy achieved by automatic inputting. When we used paper and pencil, not only was the original writing time consuming, but manual data entry was difficult because of illegible handwriting, inaccurate transcription of the numbers, inaccurate inputting into the database, and lack of available personnel for the job. The CTI system resolves all of these difficulties, but a price is paid in the loss of the dumping terminal's services. The public may be less disturbed if a terminal in a nonpublic area is used. But to the department involved, access to the database is a central part of their work and its loss severely limits their output. In fact, dependence on the automated circulation system by all departments in the library has been swift and universal even though we originally assumed the terminals outside the circulation department would be used sparingly.

Plans are being made to store personnel records in machine-readable form on diskettes. Other developments are being put on a back burner until we have less frequent need for the Apples as backups. However, LEVELS, Great Neck Library's Youth Department, has several Apples of its own on which budding "computerniks" practice their art. For them there are few limits to possible applications-perhaps only the outermost boundaries of imagination.

\section{REFERENCE}

1. Joseph Covino and Sheila Intner, "An Informal Survey of the CTI Computer Backup System," Journal of Library Automation 14:108-10 (June 1981).

\section{Computer-to-Computer Communication in the Acquisition Process}

\author{
Sandra K. PAUL: SKP Associates, New York \\ City.
}

In the 1970s, we entered the period of computer-to-computer communication; we now appear to have reached the second stage of development. Today more than seventy publishers are equipped to receive computer tape orders and input them directly to their order fulfillment systems; twenty-six publishers can produce computer invoices and credits for their customers; six are capable of sending monthly updating information about titles, prices, publication dates, and books declared out of print. All of this, however, is based on a system through which computer tapes are sent from buyer to seller and back via the United States mail. The next stepcomputer-to-terminal or computer-tocomputer communication-is just around the corner.

\section{HISTORICAL PERSPECTIVE}

How did this happen? It started in September 1974 when DeWitt C. ("Bud") Baker, newly appointed president of the Baker \& Taylor Company, envisioned the savings his company could find if their customers provided the International Standard Book Number (ISBN) on their orders. $\mathrm{He}$ also believed that the volume of paper created by the computer was expensive and time-consuming for publishers to handle. 